\title{
Origin of oxidized cellulose degradation products and mechanism of their promotion of cellobiohydrolase I biosynthesis in Trichoderma reesei
}

\author{
Kati Szakmary, ${ }^{1,2} \uparrow$ Alfred Wotawa $^{1}$ and Christian P. Kubicek ${ }^{2 *}$ \\ ${ }^{1}$ Abteilung für Biologie, Forschungszentrum Seibersdorf, and ${ }^{2}$ Abteilung für Mikrobielle Biochemie, \\ Institut für Biochemische Technologie und Mikrobiologie, TU Wien, Getreidemarkt 9, A-1060 Wien, Austria
}

(Received 22 April 1991; revised 12 August 1991; accepted 28 August 1991)

\begin{abstract}
Cellobiono-1,5-lactone (CBL) induces cellulase, particularly cellobiohydrolase I (CBH I) formation in Trichoderma reese $i$. When used as a sole source of carbon, it promoted comparably poor growth, because (a) the $\delta$ gluconolactone arising by the action of $\beta$-glucosidase is not metabolized by the fungus, and $(b)$ it is a low- $V_{\max }$ substrate of the $T$. reesei $\beta$-glucosidase. Induction of higher amounts of CBH I were observed when CBL was supplied as carbon source together with cellobiose than when supplied alone. Maximal CBH I levels formed under these conditions were comparable to those when $T$. reese $i$ was grown on cellobiose plus $\delta$-gluconolactone, an inhibitor of $\beta$-glucosidase. These data suggest an indirect effect of CBL on CBH I induction, probably by inhibiting cellobiose hydrolysis. The origin of CBL during growth of $T$. reesei on cellulose was also investigated: aldonic acids and aldonolactones were released from cellulose by $T$. reesei culture fluids. Artificially oxidized celluloses gave rise to the appearance of higher concentrations of oxidized products but the addition of cellobiose did not, suggesting that their appearance is not due to a cellobiose-oxidizing enzyme. No accumulation of oxidized cellooligosaccharides occurred when the action of both cellobiohydrolases (CBH I and II) was simultaneously blocked by monoclonal antibodies. These data suggest that cellulose already contains oxidized chain termini, and that these aldonolactones and aldonic acids are released by the action of the two cellobiohydrolases and not by a 'celluloseoxidizing' enzyme.
\end{abstract}

\section{Introduction}

The mechanism by which cellulase formation is triggered by the presence of cellulose in the fungus Trichoderma reesei has recently become a major focus of research: the presence of extracellular cellulose is 'recognized' by conidial-surface-bound constitutive cellulases (Kubicek, 1987; Kubicek et al., 1988; El Gogary et al., 1989), particularly cellobiohydrolase II (CBH II) (Messner et al., 1991), which carry out the initial attack on the cellulose molecule. The small amounts of degradation products arising thereby may then be taken up by the fungus and act as inducers of further cellulase formation (Kubicek et al., 1990).

However, the identity of the inducer(s) of cellulase formation is (are) still a matter of dispute; in resting cell systems, the disaccharide sophorose (glucosyl- $\beta$-1,2-

$\dagger$ Present address: Institut für Medizinische Biochemie, Universität Wien, Währingerstrasse 9, A-1090 Wien, Austria.

Abbreviations: CBH I, II, cellobiohydrolase I, II ; CBL, cellobiono1,5-lactone. diglucoside) and the oxidized disaccharide cellobiono1,5-lactone (CBL) were shown to be very potent inducers of cellulase formation in $T$. reesei (Mandels et al., 1962; Sternberg \& Mandels, 1979; Iyayi et al., 1989). The assumption that these components act as inducers during growth on cellulose was also supported by their detection in culture filtrates from the fungus (Mandels et al., 1962; Vaheri, $1982 a, b$ ). The formation of sophorose by either the membrane-bound $\beta$-glucosidase (Umile \& Kubicek, 1986) or the extracellular endoglucanase I (EG I, Claeyssens et al., 1990) has been demonstrated (Vaheri et al., 1979). The origin of CBL, however, is so far unclear: neither cellobiose- nor cellulose-oxidizing enzymes from $T$. reese $i$ have so far been reported. Since some oxidized cellulose ends occur naturally in cellulose (Schmidt, 1936), an enzymic mechanism for CBL formation need not necessarily be postulated. The induction of an additional low percentage of oxidized end groups into cellulose increases its inductive effect on cellulase formation by $T$. reesei (Kubicek-Pranz et al., 1990).

In the present paper we report results from investiga- 
tions, by which we attempted to find out (i) the origin of CBL formed during cellulose degradation and (ii) the mechanism by which it induces cellulase formation in $T$. reesei.

\section{Methods}

Organism. The fungal strain used throughout this study was $T$. reesei QM 9414, obtained from the American Type Culture Collection, Rockville, MD, USA (ATCC 26921). It was grown at $28^{\circ} \mathrm{C}$ for $7 \mathrm{~d}$ on malt agar slants and thereafter kept at $4{ }^{\circ} \mathrm{C}$ and subcultured monthly.

Conditions of cultivation. $T$. reesei was cultivated in shake flasks on modified Mandels-Andreotti medium as described previously (Messner \& Kubicek, 1990), using all carbon sources (autoclaved separately) at initial concentrations of $10 \mathrm{~g}^{-1}$. A volume of $200 \mathrm{ml}$ medium in 1 litre Erlenmeyer flasks was used for cultivation on a rotary shaker $\left(250\right.$ r.p.m., $\left.28^{\circ} \mathrm{C}\right)$ for the time indicated in Results and Discussion.

Inhibitors were added $8 \mathrm{~h}$ after inoculation as concentrated, membrane-filtered $(0 \cdot 22 \mu \mathrm{m})$ solutions to give final concentrations as specified in Results and Discussion.

For resting cell cultivations, $T$. reesei was pregrown on glycerol medium and then transferred to the replacement medium lacking nitrogen (and therefore not enabling growth). The entire procedure has been described in detail previously (Kubicek, 1987).

Antibody blocking experiments. To block the action of CBH I and II during incubation of mycelia or culture filtrates of $T$. reesei with cellulase, antibodies against both enzymes ( $\mathrm{CH}-5$ and $\mathrm{CE}-16$, Mischak et al., 1989; purified according to Johnston \& Thorpe, 1987) were added as follows: to $2 \mathrm{ml}$ portions of culture broth (or filtrate, as specified) pregrown on lactose for $96 \mathrm{~h}, 100 \mu \mathrm{l}$ (containing $1 \mathrm{mg} \mathrm{IgG}$ ) of both antibodies was added. After $1 \mathrm{~h}$ incubation, $10 \mathrm{mg}$ Avicel powder was added, and incubation continued with agitation $\left(50\right.$ r.p.m., $\left.30^{\circ} \mathrm{C}\right)$ for $16 \mathrm{~h}$. Broth was then centrifuged $\left(10000 \mathrm{~g}, 4^{\circ} \mathrm{C}, 15 \mathrm{~min}\right)$ and the supernatant directly used to assay aldonic acids and aldonolactones. To remove antibodies from the cellulose and cellulose plus mycelia, the debris after centrifugation was first incubated in $1 \%(\mathrm{w} / \mathrm{v})$ bovine serum albumin in $50 \mathrm{~mm}$-sodium phosphate buffer, $\mathrm{pH} 6.0\left(1 \mathrm{~h}, 30^{\circ} \mathrm{C}\right)$, followed by three washes (15 min each) with $0.5 \mathrm{M}-\mathrm{NaCl}$ in $50 \mathrm{~mm}$ sodium phosphate buffer, pH 6.0, and finally two washes (15 min each) with $50 \mathrm{~mm}$-sodium phosphate buffer, pH 6.0. Freshly harvested culture supernatant $(1.5 \mathrm{ml})$, obtained as described above, was added, mixed, and incubation continued for a further $8 \mathrm{~h}$. Aldonolactones and aldonic acids were then quantified in the supernatant.

Determination of fungal dry weight. Appropriately sized samples of the culture broth were filtered on previously tared sintered funnels (G1 porosity), washed first with 3 vols tap water, then with distilled water, and dried to constant weight at $110^{\circ} \mathrm{C}$. The biomass yield coefficient $\left(Y_{\mathrm{x} / \mathrm{s}}\right)$ is defined as $\mathrm{g}$ biomass dry weight obtained per $\mathrm{g}$ carbon source consumed. For quantifying biomass in the presence of cellulose, total mycelial protein was extracted and assayed as described by Fritscher $e t$ al. (1990).

Immunological quantification of CBH I formation. $\mathrm{CBH}$ I was assayed by a dot-blot technique, using the monoclonal antibody $\mathrm{CH}-5$ (Mischak et al., 1989), as described by John et al. (1984).

Analytical methods. To measure sugars and sugar acids chemically, $20 \mathrm{ml}$ portions from the culture filtrate were lyophilized, then taken up in $0.5 \mathrm{ml}$ distilled water and centrifuged in an Eppendorf centrifuge. Total reducing sugars were then determined by the 3,5-dinitrosalicylic

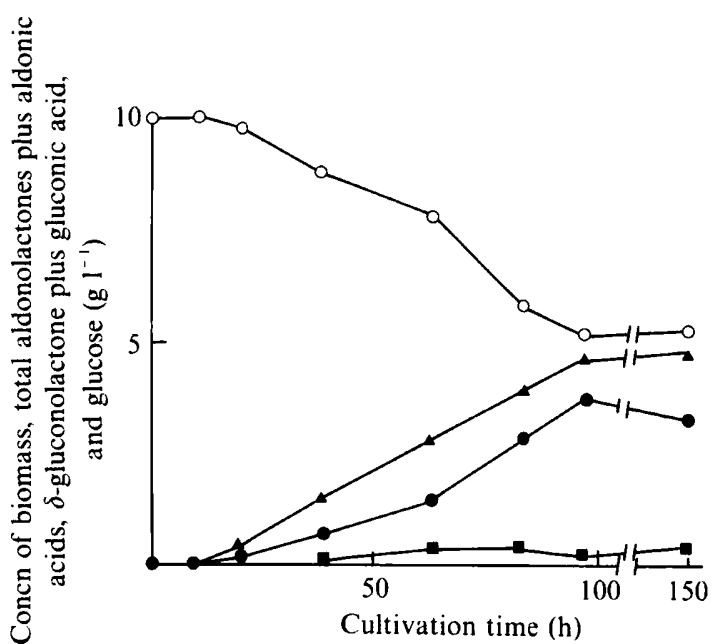

Fig. 1. Growth of $T$. reesei on $\mathrm{CBL}$ as the sole source of carbon. Biomass; $O$, total aldonolactones and aldonic acids; $\boldsymbol{\Delta}, \delta$-gluconolactone and gluconic acid; $\mathbf{\square}$, glucose. Results shown are from a single experiment, but repetitions gave consistent results.

acid (DNS) method (Miller, 1959), and total carbohydrate was assayed by the phenol/sulphuric acid method (Dubois et al., 1956). Glucose and gluconolactone plus gluconic acid were assayed enzymically using commercial test kits (Boehringer) according to the supplier's instructions. Total aldonolactones and aldonic acids were quantified as described by Bruchmann et al. (1987).

Enzyme assays. Cellulase activity was assayed by measuring 'filter paper activity' as described previously (Kubicek et al., 1988). $\beta$ Glucosidase activity was assayed as described by Messner \& Kubicek (1990). For both enzymes, 1 unit (U) indicates the release of $1 \mu \mathrm{mol}$ glucose $\mathrm{min}^{-1}$ under these conditions. To measure the hydrolysis of cellobiose specifically in the presence of CBL, the amounts of glucose, $\delta$-gluconolactone and gluconic acid formed were determined enzymically. A value corresponding to the sum of gluconic acid and $\delta$ gluconolactone was then deducted from the glucose value to calculate the release of glucose specifically from cellobiose. Both $\beta$-glucosidase preparations were free of glucose oxidase activity (unpublished data).

Purification of $\beta$-glucosidases from $T$. reesei. The extra- and the intracellular $\beta$-glucosidases from $T$. reese $i$ were purified as described by Hofer et al. (1989).

\section{Results and Discussion}

\section{Metabolism of $C B L$ in $T$. reesei and relationship to CBH I formation}

It has previously been shown that CBL promotes the synthesis of cellulases by $T$. reese $i$ when added to cultures growing on cellulose (Bruchmann et al., 1978) or to resting mycelia (Iyayi et al., 1989). In order to learn about the mechanism of this effect, we carried out some investigations on the metabolism of CBL by the fungus. $T$. reesei was able to use $\mathrm{CBL}$ as a carbon source for growth, although the molar biomass yield $\left(Y_{\mathrm{x} / \mathrm{s}}\right)$ was only about half of that for cellobiose or glucose (Table 1). 
Table 1. Growth of T. reesei on $C B L$ and other carbon sources, and $C B H$ I formation

Growth yields $\left(Y_{\mathrm{x} / \mathrm{s}}\right)$ were determined after $36 \mathrm{~h}$ cultivation. The specific growth rate $(\mu)$ is given as the mean rate of increase in biomass between $10\left(<0 \cdot 1 \mathrm{~g} \mathrm{l}^{-1}\right.$ of biomass formed) and $36 \mathrm{~h}$, and related to half the final amount of biomass formed after $36 \mathrm{~h}$. $\mathrm{CBH}$ I was quantified in culture filtrates after $36 \mathrm{~h}$ growth. Values given are means of at least three independent experiments. The reproducibility of the results quoted was within $15 \%$ of SD. ND, Not detectable.

\begin{tabular}{lccc}
\hline \hline \multicolumn{1}{c}{ Carbon source } & $Y_{\mathrm{x} / \mathrm{s}}$ & $\begin{array}{c}\mu \\
\left(\mathrm{h}^{-1}\right)\end{array}$ & $\begin{array}{c}\mathrm{CBH} \text { I } \\
\left(\mathrm{mg} \mathrm{l}^{-1}\right)\end{array}$ \\
\hline Glucose & 0.48 & $0 \cdot 18$ & $<10$ \\
Cellobiose & 0.45 & $0 \cdot 17$ & $<10$ \\
CBL & $0 \cdot 18$ & 0.06 & 43 \\
$\delta$-Gluconolactone & $\mathrm{ND}$ & $\mathrm{ND}$ & $\mathrm{ND}$ \\
Glucose plus $\delta$-gluconolactone & $0 \cdot 22$ & $0 \cdot 14$ & $<10$ \\
Cellobiose plus $\delta$-gluconolactone & $0 \cdot 18$ & 0.04 & 256 \\
Cellobiose plus CBL & 0.27 & 0.06 & 186 \\
\hline \hline
\end{tabular}

When $\delta$-gluconolactone was the only carbon source in the medium, no biomass formation was observed. This observation suggests that the low yield was due to the use of the glucose moiety in CBL only. This assumption was supported by the finding of $\delta$-gluconolactone and gluconic acid, but no glucose, in the medium (Fig. 1). Furthermore, equimolar ratios of glucose and $\delta$-gluconolactone at a total concentration similar to CBL gave a similar biomass yield $\left(Y_{\mathrm{x} / \mathrm{s}}\right)$ as CBL.

The rate of growth on CBL was markedly lower than that on cellobiose or glucose, and also lower than on a mixture of glucose and $\delta$-gluconolactone (Table 1). This suggests that either hydrolysis or uptake of CBL may limit the growth rate of $T$. reesei. In order to distinguish between these two possibilities, we incubated washed mycelia of $T$. reesei with CBL in the presence and absence of various concentrations of the $\beta$-glucosidase inhibitor nojirimycin at $\mathrm{pH} 3,4$ and 5 (Fig. 2). Nojirimycin inhibited CBL uptake incompletely. The data therefore suggest that the first steps in CBL metabolism proceed simultaneously via hydrolysis and uptake. From the extrapolation of the nojirimycin titration graph (Fig. 2) it appears that the uptake rate is of the same order as that of cellobiose (Fritscher et al., $1990)$, i.e. about $0 \cdot 1 \mu \mathrm{mol} \mathrm{min}^{-1}(\mathrm{~g} \text { dry weight })^{-1}$. The activity of $\beta$-glucosidase, however, was apparently much lower (2.3 and 0.38 for cellobiose and CBL, respectively).

In order to relate metabolism of CBL to its ability to induce cellulase formation, CBH I - the major cellulase of $T$. reesei (Enari \& Niku-Paavola, 1987) - was quantified immunologically in samples from corresponding culture filtrates (Table 1): no CBH I was found in those from growth on glucose, cellobiose or glucose plus $\mathrm{CBL}$, or glucose plus $\delta$-gluconolactone. Interestingly,

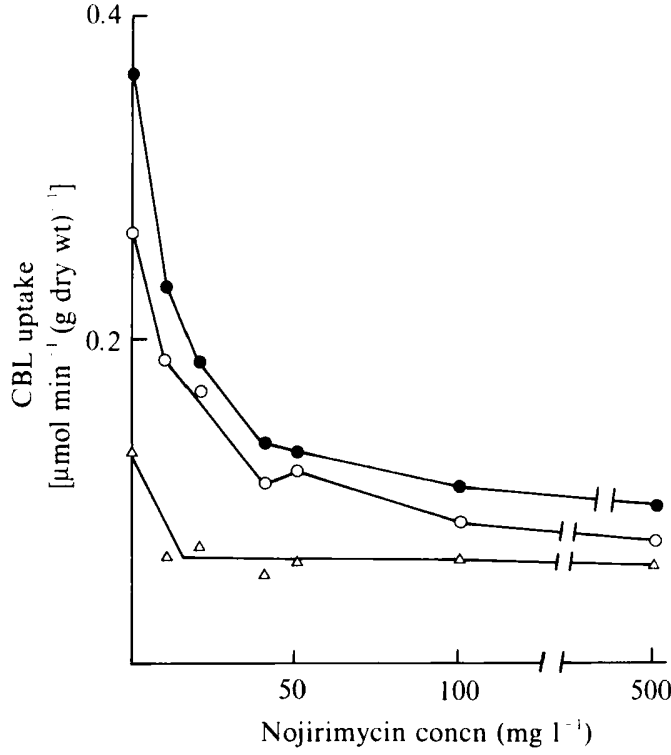

Fig. 2. Rate of uptake of $\mathrm{CBL}$ by resting mycelia of $T$. reese $i$ at $\mathrm{pH} 5$ $(\bigcirc), 4(O)$, and $3(\triangle)$ in the presence of different concentrations of nojirimycin. The rates of uptake were calculated from the differences in the concentration of CBL determined in the culture supernatant after 1 and $8 \mathrm{~h}$ incubation. Results shown are from a single experiment, but the final percentage inhibition and the respective concentration of inhibitor were within $17 \%$ of reproducibility $(n=3)$.

however, there was only a low amount of $\mathrm{CBH} I$ detectable in culture filtrates from CBL-grown $T$. reesei. Highest amounts of CBH I were found in cultures grown on cellobiose plus either CBL or $\delta$-gluconolactone. These findings suggest that the inductive action of CBL is related to its effect on cellobiose metabolism rather than to its action as an inducer.

\section{$C B L$ as a substrate of $T$. reesei $\beta$-glucosidases}

The results described above show that CBL may serve as a substrate of both the extracellular as well as - after uptake - the intracellular $\beta$-glucosidases (Inglin et al., 1980 ) from $T$. reese $i$. We have shown that $T$. reesei can be induced by cellobiose to form CBH I, if $\beta$-glucosidase is simultaneously inhibited by nojirimycin. As shown above, the addition of $\delta$-gluconolactone - a reputed inhibitor of $\beta$-glucosidases - to cellobiose-grown mycelia also promoted CBH I biosynthesis. In order to support the assumption that inhibition of $\beta$-glucosidase may also be the basis for the 'inducing effect' of CBL, its ability to serve as a substrate and inhibitor for the $T$. reesei $\beta$ glucosidase was investigated (Table 2): it is clear that CBL is a substrate for which $\beta$-glucosidase has, in comparison to cellobiose, a high affinity but a very low activity. No significant differences in this respect were observed between the two enzymes. The data described in this study confirm earlier studies of this enzyme from 


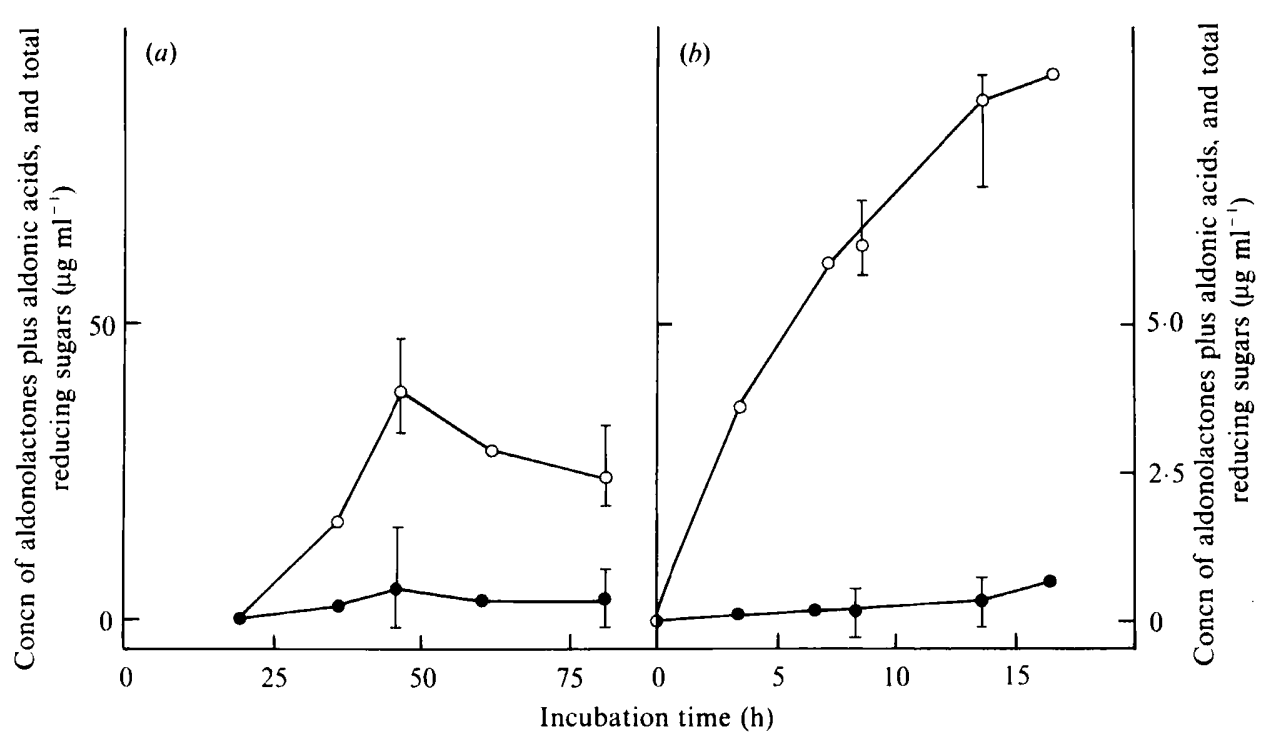

Fig. 3. Accumulation of aldonic acids and aldonolactones $(\boldsymbol{O})$ and total reducing sugars $(O)$ during $(a)$ growth of $T$. reesei on Avicel cellulose, and $(b)$ incubation of Avicel cellulose $\left(10 \mathrm{~g} \mathrm{l}^{-1}\right)$ in an undiluted culture filtrate from $T$, reesei, grown for $4 \mathrm{~d}$ on Avicel cellulose Cycloheximide and chloramphenicol (50 and $500 \mathrm{mgl}^{-1}$, respectively) were added in $(b)$ to prevent microbial contamination. Bars indicate SD $(n=4)$.
Table 2. Effect of $C B L$ on the kinetics of the extracellular and the intracellular $\beta$-glucosidase from $T$. reesei

$V_{\max }$ is expressed in $U(\mathrm{mg} \text { protein) })^{-1}$ and $K_{\mathrm{m}}$ in mM. \pm values in parentheses indicate the respective SD.

\begin{tabular}{|c|c|c|c|}
\hline \multirow[b]{2}{*}{ Substrate } & \multirow{2}{*}{$\begin{array}{c}\text { Kinetic } \\
\text { parameter }\end{array}$} & \multicolumn{2}{|c|}{$\beta$-Glucosidase } \\
\hline & & Extracellular & Intracellular \\
\hline Cellobiose & $\begin{array}{l}V_{\max } \\
K_{\mathrm{m}}\end{array}$ & $\begin{array}{cc}27 & ( \pm 5.0) \\
2.4 & ( \pm 0.5)\end{array}$ & $\begin{array}{ll}5.4 & ( \pm 1 \cdot 2) \\
3.0 & ( \pm 0.4)\end{array}$ \\
\hline CBL $(0.05 \mathrm{~mm})$ & $\begin{array}{l}V_{\text {max }} \\
K_{\mathrm{n} 1}\end{array}$ & $\begin{array}{ll}4.3 & ( \pm 0.5) \\
0.03 & ( \pm 0.01)\end{array}$ & $\begin{array}{l}0.64( \pm 0.21) \\
0.07( \pm 0.02)\end{array}$ \\
\hline $\begin{array}{l}\text { Cellobiose plus CBL } \\
(0.05 \mathrm{~mm})\end{array}$ & $\begin{array}{l}V_{\max } \\
K_{\mathrm{m}}\end{array}$ & $\begin{array}{ll}25.8 & ( \pm 6.7) \\
47.3 & ( \pm 6.8)\end{array}$ & $\begin{aligned} 4.9 & ( \pm 1 \cdot 3) \\
56 \cdot 0 & ( \pm 10 \cdot 3)\end{aligned}$ \\
\hline
\end{tabular}

other organisms (Dale et al., 1985). CBL produces a characteristic competitive type of inhibition of cellobiose hydrolysis with a corresponding $K_{\mathrm{i}}$ of $27 \pm 6 \mu \mathrm{M}$. These data suggest that CBL may stabilize the internal cellobiose pool during growth on cellulose, or resemble a gratuitous inducer when added alone to resting mycelia.

\section{$C B L$ released from cellulose induces cellulase formation in $T$. reesei}

Native cellulose is known to contain minor amounts of carboxyl groups located at the reducing ends of the cellulose chains (Schmidt, 1936; Vaheri, 1982a, b). Since CBH I and II split cellobiose units from the non-reducing ends (Enari \& Niku-Paavola, 1987), CBL may be released into the culture liquid by their action. Fig. 3(a) shows the accumulation of total aldonolactones and aldonic acids as well as reducing sugars during cultiva- tion of $T$. reesei on Avicel cellulose. In accordance with earlier studies by Vaheri $(1982 b)$ we find a ratio of reducing sugars to aldonic acids of roughly $8: 1$ during the early stage of cultivation; the release of both substance groups appeared to decrease as cultivation commenced. This may either be the result of inhibition of their formation by products formed, or be due to the increased amount of biomass already formed which can degrade both components at an increased rate. In order to test these two possibilities, the experiment was repeated with the culture supernatants only (Fig. $3 b$ ). As is demonstrated clearly, the absence of mycelium leads to the accumulation of increased amounts of reducing sugars, but only to a comparably low amount of aldonolactones or aldonic acids. Based on the rate of formation of reducing sugars, the release of oxidized compounds accounts for only $0.3 \%$ of total material from cellulose, which may well be due to a release of oxidized end groups already present in the cellulosic substrate.

In order to find out whether these oxidized products could be involved in the induction of cellulases by $T$. reesei, we first compared the accumulation of lactones from two cellulosic substrates carrying different amounts of oxidized end chains (Kubicek-Pranz et al., 1990). In accordance with these earlier results, the higher oxidized cellulose $(0.2 \%$ of additional oxidized end groups) promoted increased CBH I formation. This was paralleled by increased amounts of oxidized degradation products accumulating in the medium (Fig. 4a). In a second experiment we added CBL at different times and different concentrations to a $T$. reesei culture growing on Avicel cellulose. As shown in Fig. 4 (b), concentrations of CBL roughly resembling those observed during degrada- 


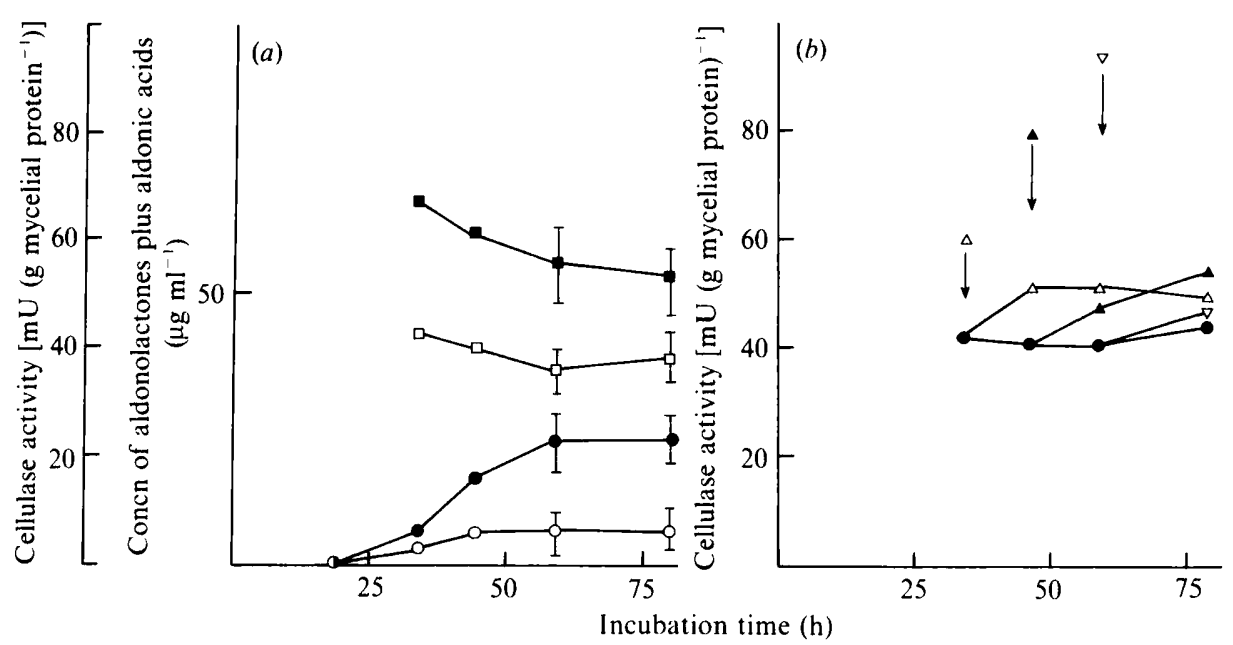

Fig. 4. (a) Accumulation of aldonic acids and aldonolactones $(\boldsymbol{O}, O)$ and cellulase formation $(\square, \square)$ during growth of $T$. reesei on oxidized Avicel cellulose $(0.2 \%$ oxidized end groups, filled symbols) and non-oxidized Avicel cellulose (open symbols). Bars indicate SD $(n=3)$. (b) Effect of addition of CBL $\left(10 \mu \mathrm{g} \mathrm{m}^{-1}\right)$ on cellulase formation by $T$. reesei growing on Avicel cellulose. CBL was added at $40(\triangle), 48$ $(\triangle)$ and $63(\nabla)$., No addition. Values of cellulase activity are given as filter paper units (U), relative to $T$. reesei mycelial protein in order to eliminate possible effects of CBL on the growth rate. tion of oxidized celluloses resulted in further stimulation of $\mathrm{CBH}$ I formation.

\section{$C B L$ is released from cellulose by $C B H I$ and $I I$}

The origin of CBL, found in $T$. reesei culture fluids, has so far not been clarified. While cellobiose-oxidizing enzymes have been detected in several fungi (Westermark \& Eriksson, 1975; Morpeth, 1985; Coudray et al., 1982; Dekker, 1982), their presence in $T$. reesei has so far not been reported. Therefore we added low concentrations (1-5 mM) of cellobiose to $T$. reesei growing on Avicel, but no increase in the concentration of aldonic acids or aldonolactones in the medium could be monitored (data not shown). We thus concluded that the cellobiose released from cellulose is not converted to CBL by $T$. reesei. Hence, its occurrence in culture filtrate must be due to release from cellulose.

In order to find out how CBL is formed from cellulose, we made use of the availability of monoclonal antibodies against the two major cellulases, CBH I and II (Mischak et al., 1989): the simultaneous addition of these two antibodies to mycelial cultures of $T$. reesei growing on cellulose, as well as to culture supernatants incubated with Avicel, inhibited the formation of aldonolactones and aldonic acids. Since these antibodies are specific for CBH I and II, we conclude that CBL found in the culture fluid during cellulose degradation originates from cellulose directly and not from the oxidation of cellobiose or other cello-oligosaccharides.

In order to find out whether the appearance of CBL is due to the release of naturally oxidized cellulose chains or to a cellulose-oxidizing enzyme from $T$. reesei, we incubated culture filtrates of $T$. reesei for $16 \mathrm{~h}$ with Avicel cellulose in the presence of antibodies against $\mathrm{CBH} I$ and
II. The cellulose was then washed extensively as described in Methods, and supplied as a substrate for hydrolysis by a new batch of cellulases in the absence of antibodies. The rationale behind this approach was that if there is a 'cellulose oxidase' present, oxidation should take place while cellulase activity is blocked by the antibodies; hence, subsequent enzymic cellulose hydrolysis should release an increased amount of oxidized products. The corresponding results did not support the presence of a cellulose oxidase in $T$. reesei culture filtrates, since comparable amounts of total lactones and lactonic acids were observed $\left(4.6\right.$ and $4.9 \mu \mathrm{g} \mathrm{ml}{ }^{-1}$, respectively, after $48 \mathrm{~h}$ ). Similar experimens using $T$. reesei mycelia instead of culture filtrates for the antibodyblocked stage provided consistent results. Hence, such an enzyme is either absent from $T$. reese $i$, or it exhibits a very low activity and contributes little to the origin of oxidized degradation products. Veness \& Evans (1989) recently showed than an enzyme preparation of $T$. reese $i$ released, among other components, minor amounts of gluconic and glucuronic acid lactone from Avicel cellulose, most probably by peroxide free radical attack. However, the results from our experiments, that addition of CBH I and II antibodies also stopped the oxidation of cellulose, do not support this view. Based on the evidence from the present paper, the oxidized components found in culture filtrates of $T$. reesei growing on cellulose (Vaheri, 1982a,b) are not due to an oxidative activity or agent formed by this fungus.

We must note that these results do not rule out the existence of a 'short fibre generating activity', as shown by Vaheri $(1982 a, b)$ and Krull et al. (1988), which requires oxygen or oxidative conditions.

This work was supported by Fond zur Förderung Wissenschaftlicher Forschung, P 7231 BIO. The generous gifts of oxidized cellulose by D. Seethaler and of nojirimycin by $\mathbf{S}$. Inouye are gratefully acknowledged. 


\section{References}

BruchmanN, E.-E., Graf, H., SaAd, A. A. \& Schrenk, D. (1978). Zur Gewinnung hochacktiver Cellulasepräparate und Optimierung der enzymatischen Cellulosehydrolyse. Chemiker-Zeitung 102, 154-155.

BruchmanN, E.-E., Schach, H. \& Graf, H. (1987). Role and properties of lactonase in a cellulase system. Biotechnology and Applied Biochemistry 9, 146-159.

Claeyssens, M., van Tilbeurgh, H., Kamerling, J. P., Berg, J., VRSANSKa, M. \& Biely, P. (1990). Studies of the cellulolytic system of the filamentous fungus Trichoderma reesei QM 9414. Substrate specificity and transfer activity of endoglucanase I. Biochemical Journal 270, 251-256.

Coudray, M.-R., Canevascini, G. \& Meier, H. (1982). Characterization of a cellobiose dehydrogenase in the cellulolytic fungus Sporotrichum thermophile. Biochemical Journal 203, 277-284.

Dale, M. P., Ensley, H., Kern, K., Sastry, K. A. R. \& Byers, L. D. (1985). Reversible inhibitors of $\beta$-glucosidase. Biochemistry 24, 35303539.

DEKKER, R. F. H. (1980). Induction and characterization of a cellobiose dehydrogenase produced by a species of Monilia. Journal of General Microbiology 120, 309-316.

Dubois, M., Gilles, K. A., Hamilton, J. K., Rebers, P. A. \& Smith, F. (1956). Colorimetric method for determination of sugars and related substances. Analytical Chemistry 28, 350-356.

El-Gogary, S., Leite, A., Crivellaro, O., Eveleigh, D. E. \& ElDORRY, H. (1989). Mechanism by which cellulose triggers cellobiohydrolase I gene expression in Trichoderma reesei. Proceedings of the National Academy of Sciences of the United States of America 86, 6138-6141.

ENaRI, T.-M. \& NikU-PaAvola, M.-L. (1987). Enzymatic hydrolysis of cellulose: is the current theory of the mechanisms of hydrolysis valid? CRC Critical Reviews in Biotechnology 5, 67-87.

Fritscher, C., Messner, R. \& Kubicex, C. P. (1990). Cellobiose metabolism and cellobiohydrolase I biosynthesis by Trichoderma reesei. Experimental Mycology 14, 451-461.

Hofer, F., Weissinger, E., Mischak, H., Messner, R., MeixnerMONORI, B., VisSER, J., BlaAs, D. \& KubiceK, C. P. (1989). A monoclonal antibody against the extracellular $\beta$-glucosidase from Trichoderma reesei: reactivity with other Trichoderma $\beta$-glucosidases. Biochimica et Biophysica Acta 992, 298-306.

Inglin, M., Feinberg, B. A. \& Loewenberg, J. R. (1980). Partial purification and characterization of a new intracellular $\beta$-glucosidase of Trichoderma reesei. Biochemical Journal 185, 515-519.

IYAYI, C. B., BRUCHMANN, E.-E. \& KUBICEK, C. P. (1989). Induction of cellulase formation in Trichoderma reesei by cellobiono-1,5-lactone. Archives of Microbiology 151, 326-330.

John, R., SCHIEbleR, W. \& GreEnGARD, P. (1984). A quantitative dotblot immunobinding assay for proteins using nitrocellulose membrane filters. Proceedings of the National Academy of Sciences of the United States of America 81, 1684-1687.

JOHNSTON, A. \& THORPE, R. (1987). Immunochemistry in Practice, 2nd Edn. Oxford: Blackwell Scientific Publications.

Krull, L. H., Dintzis, F. R., Griffin, H. L. \& BaKer, F. L. (1988). A microfibril-generating factor from the cellulase of Trichoderma reesei. Biotechnology and Bioengineering 31, 321-327.

KUBICEK, C. P. (1987). Involvement of a conidial endoglucanase and a plasma-membrane-bound $\beta$-glucosidase in the induction of endoglucanase synthesis in Trichoderma reesei. Journal of General Microbiology 133, 1481-1487.
Kubicek, C. P., Mühlbauer, G., Klotz, M., John, E. \& KubicekPranz, E. M. (1988). Properties of a conidial-bound cellulase enzyme system from Trichoderma reesei. Journal of General Microbiology 134, 1215-1222.

Kubicek, C. P., Messner, R., Fritscher, C., Strauss, S. \& KubicekPranz, E. M. (1990). Regulatory aspects of formation and secretion of cellulases by Trichoderma reesei. In Trichoderma Cellulases: Biochemistry, Physiology, Genetics and Applications. pp. 81-101. Edited by C. P. Kubicek, D. E. Eveleigh, H. Esterbauer, W. Steiner \& E. M. Kubicek-Pranz. Cambridge, UK: Royal Society of Chemistry Press.

Kubicek-Pranz, E. M., Steiner, M. \& Kubicek, C. P. (1990). Stimulatory effect of oxidized celluloses on cellulase formation in Trichoderma reesei. FEMS Microbiology Letters 68, 273-278.

Mandels, M., Parrish, F. W. \& Reese, E. T. (1962). Sophorose as an inducer of cellulase in Trichoderma viride. Journal of Bacteriology 83, $400-408$.

MESSNER, R. \& KUBICEK, C. P. (1990). Evidence for a single, specific $\beta$ glucosidase in cell walls from Trichoderma reesei. Enzyme and Microbial Technology 12, 685-690.

Messner, R., Kubicek-Pranz, E. M., Gsur, A. \& Kubicek, C. P. (1991). Cellobiohydrolase II is the main conidial-bound cellulase in Trichoderma reesei and other Trichoderma strains. Archives of Microbiology 155, 601-606.

MilleR, G. L. (1959). Use of dinitrosalicylic acid reagent for determination of reducing sugars. Analytical Chemistry 31, 426-428.

Mischak, H., Hofer, F., Messner, R., Weissinger, E., Hayn, M., Tomme, P., Esterbauer, H., Küchler, E., Claeyssens, M. \& KUBICEK, C. P. (1989). Monoclonal antibodies against different domains of cellobiohydrolase I and II from Trichoderma reesei. Biochimica et Biophysica Acta 990, 1-7.

MORPETH, F. F. (1985). Some properties of cellobiose oxidase from the white rot fungus Sporotrichum pulverulentum. Biochemical Journal 228, 557-564.

SCHMIDT, E. (1936). Zur Kenntnis der Cellulose nativer Zusammensetzung aus Baumwolle. Berichte der Deutschen Chemischen Gesellschaft 69, 366-377.

STERnBerG, D. \& Mandels, G., R. (1979). Induction of cellulolytic enzymes in Trichoderma reesei by sophorose. Journal of Bacteriology 139, 761-769.

UMILE, C. \& KUBICEK, C. P. (1986). A constitutive plasma membrane bound $\beta$-glucosidase in Trichoderma reesei. FEMS Microbiology Letters 34, 291-295.

VAHERI, M. P. (1982a). Oxidation as a part of degradation of crystalline cellulose by Trichoderma reesei. Journal of Applied Biochemistry 4 , 356-363.

VAHERI, M. P. (1982b). Acidic degradation products of cellulose during enzymatic hydrolysis by Trichoderma reesei. Journal of Applied Biochemistry 4, 153-160.

VAHERI, M. P., Leisola, M. \& KaUPinNen, V. (1979). Transglycosylation products of the cellulase system of Trichoderma reesei. Biotechnology Letters 1, 41-46.

VENESS, R. G. \& EVANS, C. S. (1989). The role of hydrogen peroxide in the degradation of crystalline cellulose by basidiomycete fungi. Journal of General Microbiology 135, 2799-2806.

Westermark, U. \& Eriksson, K.-E. (1975). Purification and properties of cellobiose : quinone oxidoreductase from Sporotrichum pulverulentum. Acta Chemica Scandinavica B29, 419-424. 